\title{
Anodic stripping voltammetric methods for determination of brexpiprazole and its elec- trochemical oxidation behavior in pure form and pharmaceutical preparations
}

\author{
Fathy M. Salama ${ }^{1}$, Khalid A.M. Attia $^{1}$, Manal A. El-Shal ${ }^{2}$, Ragab A. M. Said ${ }^{1}$, Ahmed El-Olemy ${ }^{1}$ and Ahmed M. Abdel-Raoof ${ }^{1, *}$ \\ ${ }^{1}$ Pharmaceutical Analytical Chemistry Department, Faculty of Pharmacy, Al-Azhar University,11751, Nasr City, Cairo, Egypt \\ ${ }^{2}$ National Organization for Drug Control and Research (NODCAR), P. O. B 29 Cairo, Egypt
}

Corresponding Author Email: Ahmedmeetyazeed79@yahoo.com

\begin{abstract}
The voltammetric behavior of brexpiprazole (BRX) was studied using cyclic voltammetry $(C V)$, anodic stripping differential pulse (AS-DP) and anodic stripping square wave (AS-SWV) voltammetry at novel functionalized carbon paste electrode (FCPEs). Electrochemical oxidation behavior of brexpiprazole shows irreversible anodic peak at $0.87 \mathrm{~V}$ versus $\mathrm{Ag} / \mathrm{AgCl}$, in Britton-Robinson buffer (BR) at pH 4.0, 50s preconcetration time and -0.5 deposition potential. The peak current concentration relationship was rectilinear over the ranges of $6.64 \times 10^{-7}-3.2 \times 10^{-6}$ and $6.64 \times 10^{-}$ ${ }^{8}-3.2 \times 10^{-7} \mathrm{~mol} \mathrm{~L}^{-1}$ with a minimum detection limit of $1.74 \times 10^{-7}$ and $1.32 \times 10^{-8}$ mol $L^{-1}$ for AS-DP and AS-SWV respectively, The proposed methods have been applied successfully for the analysis of the drug in pure and in its dosage forms.
\end{abstract}

Keywords: Anodic stripping, Differential Pulse Voltammetry, Square Wave Voltammetry, Brexpiprazole

Received: February-08-2018, Accepted: November-25-2018, https://doi.org/10.14447/jnmes.v22i2.a05

\section{INTRODUCTION}

Brexpiprazole The drug received FDA approval for the treatment of schizophrenia and for adjunctive use for the treatment of major depressive disorder (mental disorder with low mode for at least two weeks) due to its dopamine D2 receptor partial agonist effect based on a clinical trial development programme that included two pivotal Phase III trials of brexpiprazole monotherapy in acute schizophrenia (1). This drug has high affinity for 5-HT1A, 5-HT2A, D2 and $\alpha 1 \mathrm{~B}$, $2 \mathrm{C}$ receptors. It displays partial agonism at 5-HT1A and D2 receptors and potent antagonism at 5-HT2Aand $\alpha 1 \mathrm{~B}, 2 \mathrm{C}$ adrenergic receptors. It also has some affinity (antagonism) for D3, 5-HT2B, 5-HT7 and $\alpha 1 \mathrm{~A}$, $1 \mathrm{D}$ receptors, and moderate affinity for $\mathrm{H} 1$ and low affinity for M1 receptors. It has antipsychotic effect to improve the sleep patterns and cognitive performance; also, it has the potential to treat anhedonia (a loss of capacity to feel pleasure) and cognitive deficits as core symptoms in major depressive disorder and schizophrenia with a few side effects. Usually augmented with other typical and some atypical antipsychotics drugs to improve both positive and negative symptoms (2).

Brexpiprazole is chemically designated as $7-\{4-[4-(1-$ benzothiophen-4-yl) piperazin-1-yl]butoxy\}-1,2-dihydroquinolin-2one. Its molecular formula is $\mathrm{C}_{25} \mathrm{H}_{27} \mathrm{~N}_{3} \mathrm{O}_{2} \mathrm{~S}$, and its molecular weight is 433.57. Brexpiprazole is a white-to-off white powder. It is practically insoluble in water and freely soluble in methanol [3]. A review of the literature revealed that a few analytical methods have been described for the determination of brexpiprazole in pharmaceutical by HPLC method [4], and in human urine sample with its metabolites using liquid chromatography-quadrupole time-of-flight mass spectrometry (LC-QTOF).[5]

Up to date there is no study dealing with electrochemical behavior of BRX based on its oxidation or reduction, one aim of the present study was the investigation of electrochemical oxidation behavior of BRX using voltammetric methods. Development of new validated stripping voltammetric determination methods for the assay of BRX in pure form and pharmaceutical preparations. The proposed methods are more sensitive for determination of the drug in nanomolar concentration in comparison to the reported HPLC methods. The electroanalytical technique provides the advantages of simplicity, high sensitivity, low cost and relatively short analysis time, without any derivatization, extraction or clean-up steps $[6,7]$.

\section{EXPERIMENTAL}

\section{Apparatus}

- Metrohm electroanalyzers Model 797VA Computrace. The measurements were recorded using VA Computrace version 1.3.1.

- Jenway, $3510 \mathrm{pH}$ meter (Jenway, USA).

- Hot plate (Torrey pines Scientific, USA).

- Centrifuge (TDL-60B) with max speed $6000 \mathrm{r} / \mathrm{min}$. bench top (Hunan, China, Mainland).

- Functionalized carbon paste electrode as the working electrode, a $\mathrm{Ag} / \mathrm{AgCl}(3 \mathrm{M} \mathrm{KCl})$ electrode as the reference electrode, and a platinum wire as the auxiliary electrode.

\subsection{Materials and chemicals \\ 2.1.1. Pure sample}

Standard brexpiprazole powder was kindly supplied by Al-Andalus Pharmaceutical Company, Cairo, Egypt.

\subsubsection{Pharmaceutical preparation}

Rexulti ${ }^{\circledR}$ tablets, each tablet claimed to contain $4 \mathrm{mg}$ of brexpiprazole, (B. No.- R01230382) manufactured by Otsuka Pharmaceutical Company, purchased from USA market.

\subsubsection{Reagents and chemicals}

- All chemicals used were of analytical grade, water used throughout the procedure was freshly bidistilled.

- Methanol and ethanol were analytical grade (Sigma-Aldrich, Germany). 


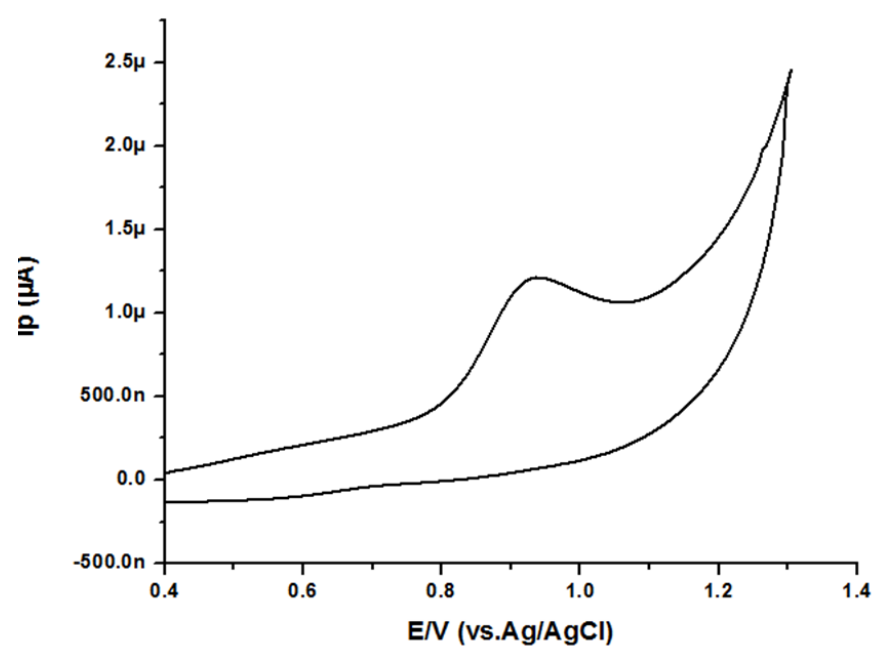

Fig. 1. Cyclic voltammogram of $1.31 \times 10^{-5} \mathrm{~mol} \mathrm{~L}^{-1} \mathrm{BRX}$ in BR buffer of $\mathrm{pH} 4$ at scan rate of $100 \mathrm{mV} \mathrm{s}^{-1}$ recorded at FCPEs.

- Orthophosphoric acid prepared as $0.04 \mathrm{M}$ aqueous solution (Prolabo, Paris, France).

- Boric and acetic acids were prepared as $0.04 \mathrm{M}$ aqueous solutions (Sigma-Aldrich, Germany).

- Sodium hydroxide prepared as $0.2 \mathrm{M}$ and $1 \mathrm{M}$ aqueous solutions (ElNasr Company, Egypt). Britton Robinson (BR) buffer 0.04 M, was prepared by mixing the acid mixture containing $0.04 \mathrm{M}$ phosphoric acid, $0.04 \mathrm{M}$ acetic acid and $0.04 \mathrm{M}$ boric acid [8]. Buffer solutions were adjusted with the appropriate amount of $0.2 \mathrm{M}$ sodium hydroxide to get the desired $\mathrm{pH}$.

- Nitric acid $(55.5 \% \mathrm{w} / \mathrm{w})$, sulfuric $(98 \% \mathrm{w} / \mathrm{w})$ and ammonium sulfate powder were obtained from (El-Nasr Company, Egypt).

- High purity graphite powder (10-20 $\mu \mathrm{m})$ and multi-wall carbon nanotubes (MWCNTs) powder (carbon $>95.0 \%$, O.D. x L 6-9 nm x 5 $\mu \mathrm{m}$ ), were obtained from (Sigma-Aldrich, Germany).

\subsection{Standard drug solutions}

Stock drug solution $\left(10^{-3} \mathrm{~mol} \mathrm{~L}^{-1}\right)$ was prepared by dissolving 43.3 $\mathrm{mg}$ of BRX in $70 \mathrm{~mL}$ of methanol and the volume was completed to $100 \mathrm{~mL}$ with the same solvent. BRX working standard solutions were prepared daily by dilution of the stock solution with methanol

\subsection{Procedures}

2.3.1. Preparation of functionalized multi-walled carbon nanotubes

$0.5 \mathrm{~g}$ MWCNTs were refluxed with $\mathrm{H}_{2} \mathrm{SO}_{4}+\mathrm{HNO}_{3}(3: 1)$ at $55{ }^{\circ} \mathrm{C}$ for 12 hours. The reaction mixture was stirred at $40{ }^{\circ} \mathrm{C}$ for 12 hours and diluted three times with $100 \mathrm{~mL}$ distilled water, filtered using centrifuge machine having 4,000 rpm. The process of centrifugation and washing off with distilled water repeated several times till neutral $\mathrm{pH}$. Then the sample dried in vacuum oven at $60{ }^{\circ} \mathrm{C}$ for 24 hours to give carboxylated MWCNTs (MWCNTs-COOH). This leads to opening the caps of MWCNTs and formation of functionalized carbon nanotubes $[9,10]$.

\subsubsection{Functionalized carbon paste electrode fabrica- tion (FCPEs):}

The carbon paste was prepared by mixing $0.49 \mathrm{~g}$ graphite powder and $10 \mathrm{mg}$ MWCNTs-COOH with $0.3 \mathrm{~mL}$ of paraffin oil in an agate mortar with a pestle. A portion of composite carbon paste was packed

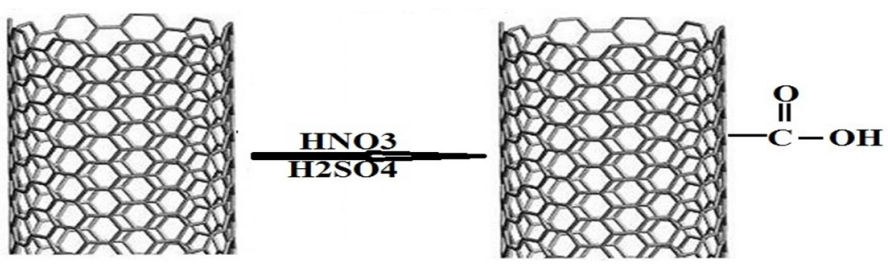

Fig. 2. Reaction takes place during functionalization and sensing response

into the hole of the insulin syringe body with diameter $3.0 \mathrm{~mm}$ which contacted with the apparatus through a copper wire. The fresh electrode surface was obtained by polishing the tip of the electrode against a weighing paper until it had a smooth and shiny surface appearance.

\subsubsection{Electrochemical measurement}

A $15 \mathrm{~mL}$ volume of BR buffer solution $(\mathrm{pH}=4)$ containing a suitable amount of BRX was added to the sample cell to cover the final concentration ranges of $6.64 \times 10^{-7}-3.2 \times 10^{-6}$ and $6.64 \times 10^{-8}-3.2 \times 10^{-7} \mathrm{~mol}$ $\mathrm{L}^{-1}$ for AS-DP and AS-SWV respectively. The test solutions were purged with a stream of nitrogen for $5 \mathrm{~min}$. The working electrode was left at the optimum deposition potential for a given time period, and stirred at about $2000 \mathrm{rpm}$ during the selected accumulation period. The stirring was then stopped and the solution allowed to rest for $5 \mathrm{~s}$, after which a scan was carried out towards positive potentials over the range between 0.4 to $1.3 \mathrm{~V}$, and the voltammograms were recorded. The experimental conditions for anodic stripping differential pulse voltammetry (AS-DP) were: pulse time, $0.04 \mathrm{~s}$; voltage step, $0.006 \mathrm{~V}$; pulse amplitude, $0.050 \mathrm{~V}$; sweep rate, $0.040 \mathrm{~V} \mathrm{~s}^{-1}$; and voltage step time, 0.153 $\mathrm{s}$. The experimental conditions for anodic stripping square wave voltammetry (AS-SWV) were: amplitude, $0.020 \mathrm{~V}$; voltage step, $0.006 \mathrm{~V}$; sweep rate, $0.03 \mathrm{~V} \mathrm{~s}^{-1}$ and frequency, $5.0 \mathrm{~Hz}$.

\subsubsection{Application to pharmaceutical formulation}

Twenty Rexulti ${ }^{\circledR} 4 \mathrm{mg}$ tablets were accurately weighed and finely powdered, then a quantity equivalent to $43.3 \mathrm{mg}$ of BRX was shaken with $50 \mathrm{~mL}$ of methanol for 10 minutes then filtered into $100 \mathrm{~mL}$ volumetric flask and the volume was adjusted to the mark with methanol to obtain a concentration of $\left(1 \times 10^{-3} \mathrm{~mol} \mathrm{~L}^{-1}\right)$. Aliquots of the drug solution were introduced into the electrolytic cell and the general procedure was carried out.

\section{RESULTS AND DISCUSSION}

\subsection{Cyclic voltammogram}

The cyclic voltammetric behavior of BRX at functionalized carbon paste electrode was studied (Fig. 1). BRX gave only an oxidation peak. On reverse scan, no reduction peak was observed; indicating that oxidation of BRX is an irreversible process at functionalized carbon paste electrode.

\subsection{Effect of the functionalization of multi-wall car- bon nanotubes}

The performance characteristics of a given working electrode depend to a large extent on the nature and its composition; also, functionalization of CNTs overcomes slow and incomplete recovery of a bare CNTbased sensor and improves the interfacial interaction. The polar groups attached to the nanotubes surface increase the adsorption affinity of the electron-donor or acceptor due to their high surface-to-volume ratio and all these lead to enhancement of their sensing performance. Functionalized CNTs can be represented by Fig. 2 and characterized by FTIR 

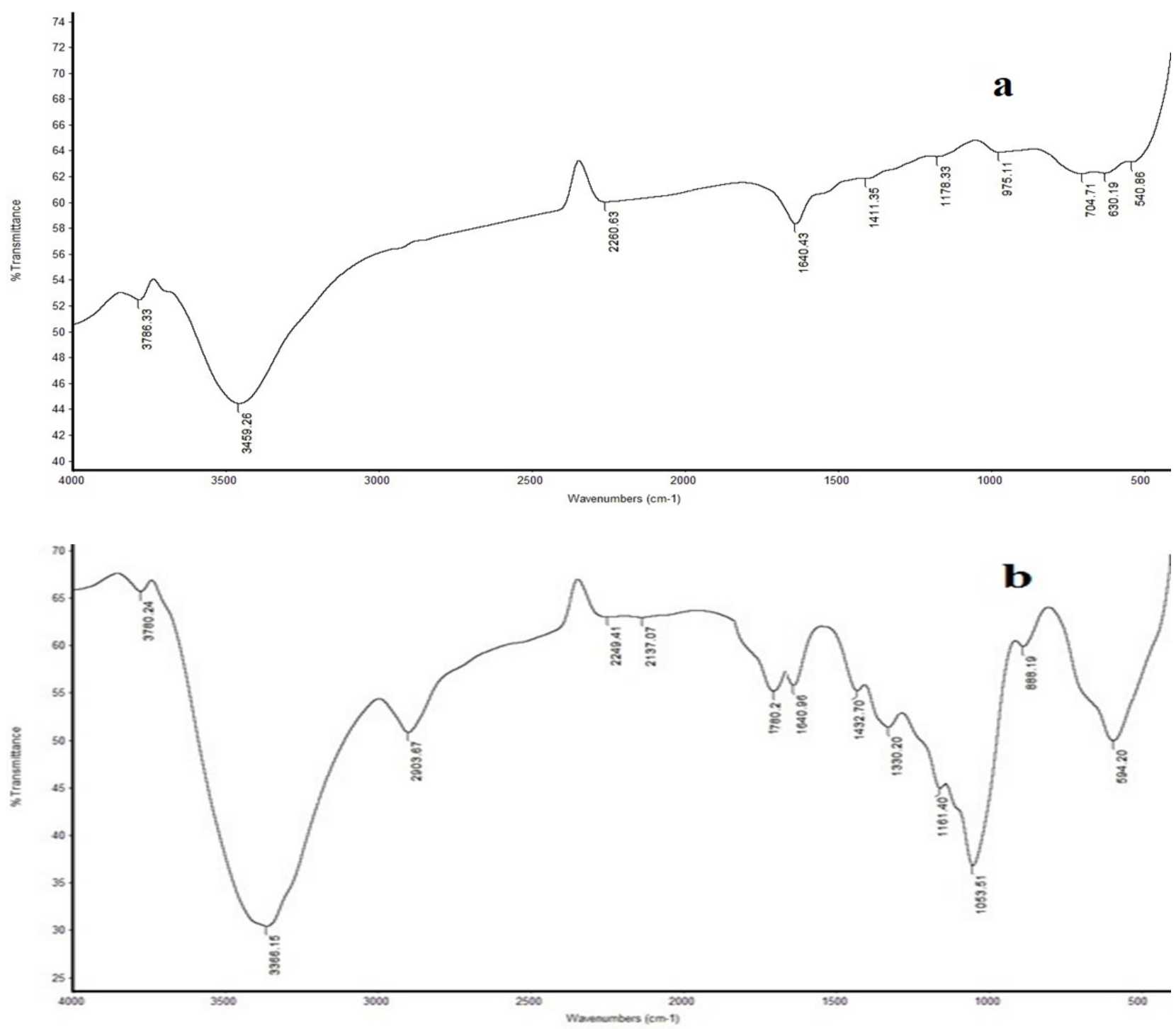

Fig. 3. FT-IR spectra of the (a) MWCNTs and (b) MWCNT-COOH powder samples.

\subsection{Fourier Transform Infrared (FT-IR) Studies}

FTIR spectra from the MWCNTs show a broad peak at $3459 \mathrm{~cm}^{-1}$ which is a characteristic of the $\mathrm{OH}$ stretch of hydroxyl group while carboxyl group on the surface of bare CNTs could be due to the partial oxidation of the surface of CNTs during purification by the manufacturer. Figure 3 shows the FT-IR spectra of the bare CNTs and functionalized CNTs. Figure. 2(b) shows other characteristic peaks of CNT$\mathrm{COOH}$ at $1053 \mathrm{~cm}^{-1}(\mathrm{C}-\mathrm{O}) 1640 \mathrm{~cm}^{-1}(\mathrm{C}=\mathrm{C})$ and $1760 \mathrm{~cm}^{-1}(\mathrm{C}=\mathrm{O})$. As compared with the FT-IR spectrum of CNTs (Fig. 3 (a)), appearance of new peaks at 1760 and $1053 \mathrm{~cm}^{-1}$ in Fig. 3(b) due to the stretching vibration of $\mathrm{C}=\mathrm{O}$ and $-\mathrm{C}-\mathrm{O}$ groups in the carboxyl group $(-\mathrm{COOH})$, respectively.

Fig. 4 shows the cyclic voltammograms of $1.31 \times 10^{-5} \mathrm{~mol} \mathrm{~L}^{-1}$ of BRX in BR buffer $\mathrm{pH} 4$ at scan rate of $100 \mathrm{mVs}^{-1}$ at CPEs and FCPEs. At $\mathrm{CPE}$ electrode, the oxidation peak was observed at $0.87 \mathrm{~V}$ with current response $0.37 \mu \mathrm{A}$. Whereas at FCPEs, the current response increases to $0.48 \mu \mathrm{A}$ (Fig.4) due to the enhancement of the electron transfer process and a larger intrinsic surface area of the functionalized electrode to amplify electrochemical signal and play a critical role in the enhancement of the electrochemical reaction.

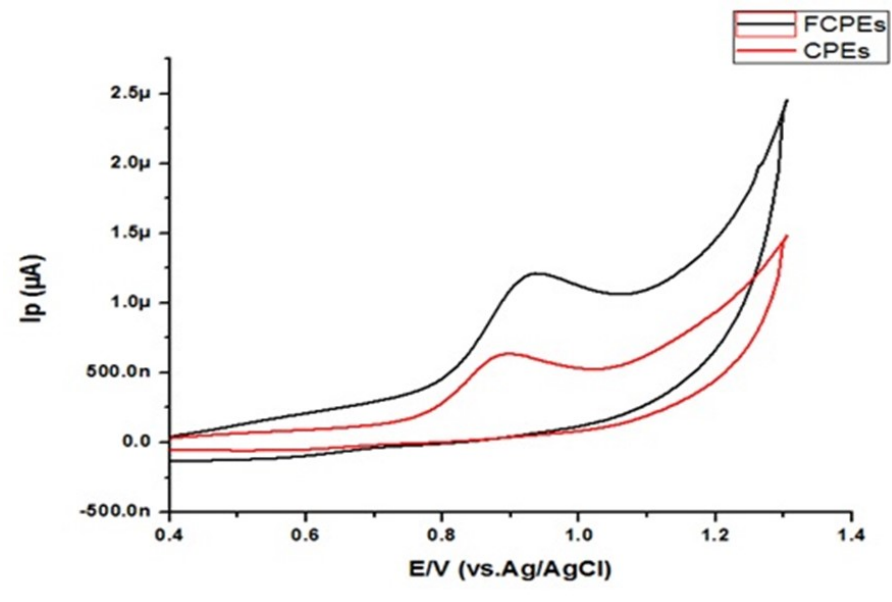

Fig. 4. Cyclic voltammograms of $1.31 \times 10^{-5} \mathrm{~mol} \mathrm{~L}^{-1} \mathrm{BRX}$ in BR buffer of $\mathrm{pH} 4$ at scan rate of $100 \mathrm{mV} \mathrm{s}^{-1}$ recorded at different working electrodes: CPEs and FCPEs. 


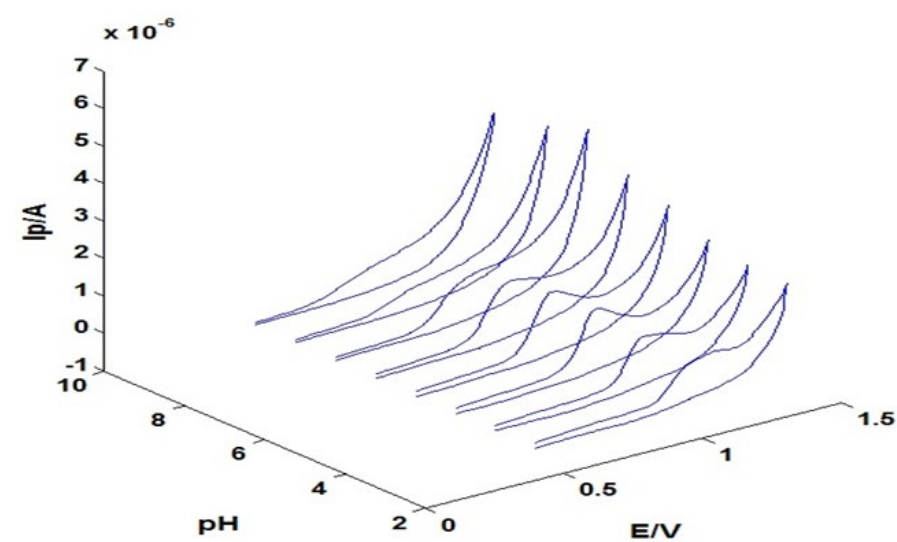

Fig. 5. The plot of the oxidation peak potential vs. $\mathrm{pH}$ of $1.31 \times 10^{-5}$ mol L $\mathrm{L}^{-1} \mathrm{BRX}$ at FCPEs

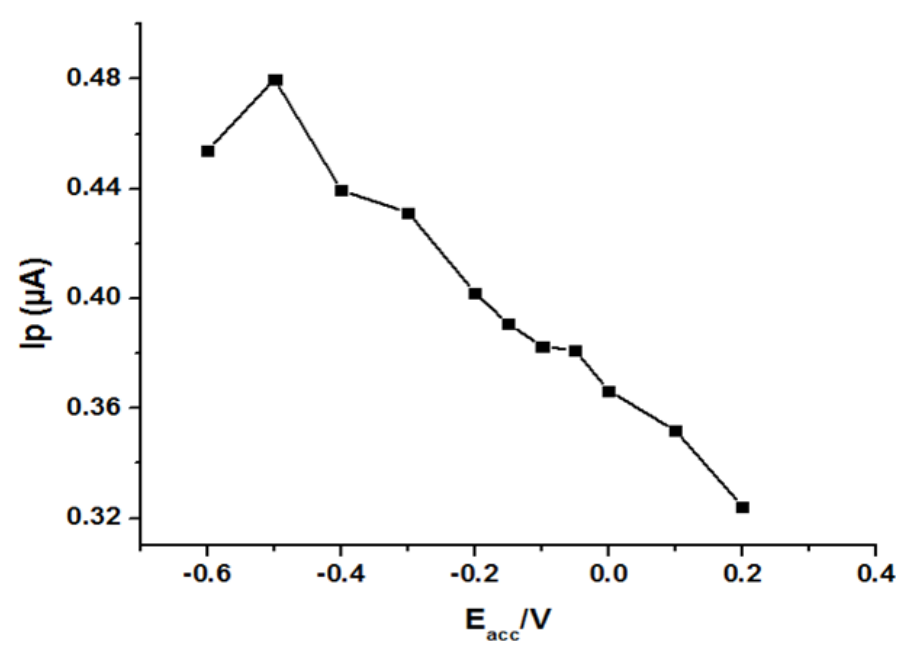

Fig. 6. Effect accumulation potential on the oxidation peak potential of $1.31 \times 10^{-5} \mathrm{~mol} \mathrm{~L}^{-1} \mathrm{BRX}$ at FCPEs.

\subsection{Area of electrodes}

The active surface area of the electrodes can be determined using the $\mathrm{CV}$ method using $20.0 \mathrm{mM} \mathrm{K} \mathrm{K}_{3} \mathrm{Fe}(\mathrm{CN})_{6}$ as a probe at different scan rates. For a reversible reaction, Randles-Sevcik equation can be applied: [11-14].

$$
\mathrm{I}_{\mathrm{P}}=\left(2.69 \times 10^{5}\right) \mathrm{n}^{3 / 2} \mathrm{ACD}^{1 / 2} \mathrm{v}^{1 / 2}
$$

Where, Ip refers to the anodic peak current, $\mathrm{n}$ is the number of electrons transferred, $\mathrm{A}$ is the active surface area of the electrode $\left(\mathrm{cm}^{2}\right), \mathrm{D}$ $=$ diffusion coefficient $\left(\mathrm{cm}^{2} / \mathrm{s}\right) \mathrm{C}=$ is the concentration of $\mathrm{K}_{3} \mathrm{Fe}(\mathrm{CN})_{6}$ $\left(\mathrm{mol} / \mathrm{cm}^{3}\right)$, and $v=$ potential scan rate $(\mathrm{V} / \mathrm{s})$. for $20.0 \mathrm{~mm} \mathrm{~K}_{3} \mathrm{Fe}(\mathrm{CN})_{6}$ in $0.1 \mathrm{M} \mathrm{KCl}$ electrolyte, $\mathrm{n}=1, \mathrm{D}=7.6 \times 10^{-6} \mathrm{~cm}^{2} \mathrm{~s}^{-1}$, then the active surface area of the electrodes was calculated from the slope of the plot of Ip vs. $v^{1 / 2}$ and was found to be 0.044 and $0.148 \mathrm{~cm}^{2}$ for bare CPEs and functionalized electrode respectively, which explain the enhancement of anodic oxidation peak in case of FCPEs.

\section{5. pH effect}

The oxidation mechanism of BRX is depending on $\mathrm{pH}$ of the solution and this was obvious from negatively shifting in anodic peak potential with increasing of the solution $\mathrm{pH}$ which explains that protons participate in their electrode reaction processes figure.5. through the

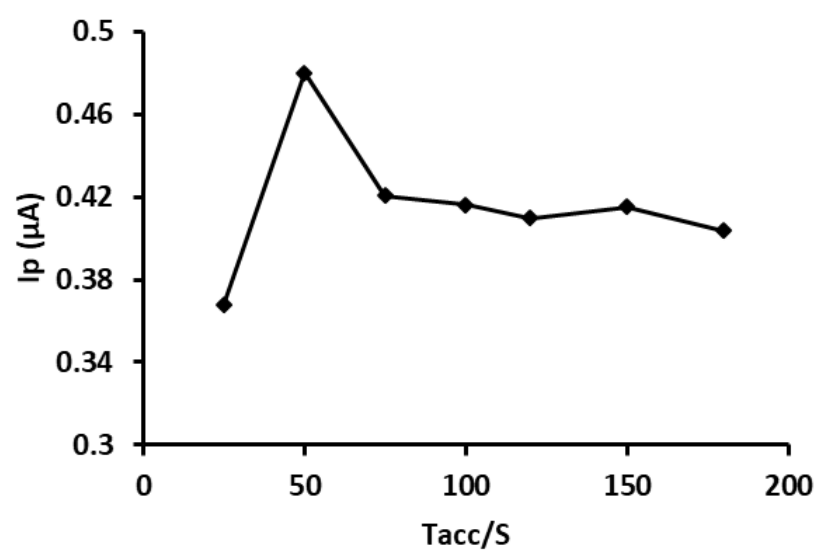

Fig. 7. Effect accumulation time on the oxidation peak potential at of $1.31 \times 10^{-5} \mathrm{~mol} \mathrm{~L}^{-1}$ BRX FCPEs.

loss of two lone pair of electrons and one proton attached to nitrogen atom in the piperazine ring. The peak potential for BRX oxidation varies linearly with $\mathrm{pH}$ (over the $\mathrm{pH}$ range $2-6$ ) which fit to the linear regression equations of $\mathrm{E}(\mathrm{V})=0.986-0.028 \mathrm{pH}$, with determination coefficient $\left(\mathrm{r}^{2}\right)=0.9949$ The highest oxidation peak current was obtained at $\mathrm{pH}$ 4. At higher $\mathrm{pH}$ values after 6.0, peak potential values were $\mathrm{pH}$ independent. In medium having $\mathrm{pH}$ higher than 6.0, solubility of BRX decreases sharply and formation of precipitation occurs, hence at higher $\mathrm{pH}$, electrochemical behavior of BRX was not studied. The slopes were found to be $-0.028 \mathrm{mV}$ per $\mathrm{pH}$ units and that was evidence that the number of transferred electrons and protons included in this mechanism is not equal. From the results obtained, the BR buffer of $\mathrm{pH}$ 4 was selected as the optimum $\mathrm{pH}$ used in further experiments (Fig. 5).

\subsection{Effect of the accumulation potential}

The effect of accumulation potential has been studied by the $\mathrm{CV}$ method (Fig. 6) shows the peak current vs. accumulation potential using $1.31 \times 10^{-5} \mathrm{~mol} \mathrm{~L}^{-1}$ of BRX at FCPs, at $\mathrm{v}=-0.5 \mathrm{~V} \mathrm{~s}^{-1}$, and $\mathrm{t}_{\mathrm{acc}}=50 \mathrm{~s}$ in BR buffer. In order to determine an ideal accumulation potential, the starting potential was varied in the range -0.6 to $+0.2 \mathrm{~V}$ after an accumulation time of $50 \mathrm{~s}$, upon negative shifting of the starting potential in the range +0.2 to $-0.6 \mathrm{~V}$, the peak current increases. This means that the mechanism of BRX accumulation is mainly due to electrostatic attraction on electrodes. The optimum accumulation potential value Eacc was determined to be $-0.5 \mathrm{~V}$ where The peak current reached to its maximum value and at this point it will be suitable for quantitative analysis.

\subsection{Effect of the accumulation time}

The effect of accumulation time has been studied by the CV method (Fig. 7) shows the peak current vs. accumulation time using $1.31 \times 10^{-5}$ mol L $\mathrm{L}^{-1}$ of BRX at FCPs, at $\mathrm{v}=0.1 \mathrm{Vs}^{-1}$, and $\mathrm{E}_{\mathrm{acc}}=-0.5 \mathrm{~V}$ in BR buffer. The influence of accumulation time ranging between 25 and $180 \mathrm{~s}$ has been studied. The optimum accumulation time value $t_{\text {acc }}$ was determined to be $50 \mathrm{~s}$ where The peak current reached to its maximum value and at this point it will be suitable for quantitative analysis.

\subsection{Effect of scan rate}

The influence of scan rate $v$ (ranging from 20 to $200 \mathrm{mV} \mathrm{s}^{-1}$ ) on the oxidation peak currents of BRX $\left(1.31 \times 10^{-5} \mathrm{~mol} \mathrm{~L}^{-1}\right)$ was examined at FCPEs in BR buffer ( $\mathrm{pH} \mathrm{4}$ ) and a linear relationship is found for the logarithm of the oxidation peak currents and the logarithm of the scan rates (Fig. 8). The oxidation peak current increases linearly with the linear regression equation as 


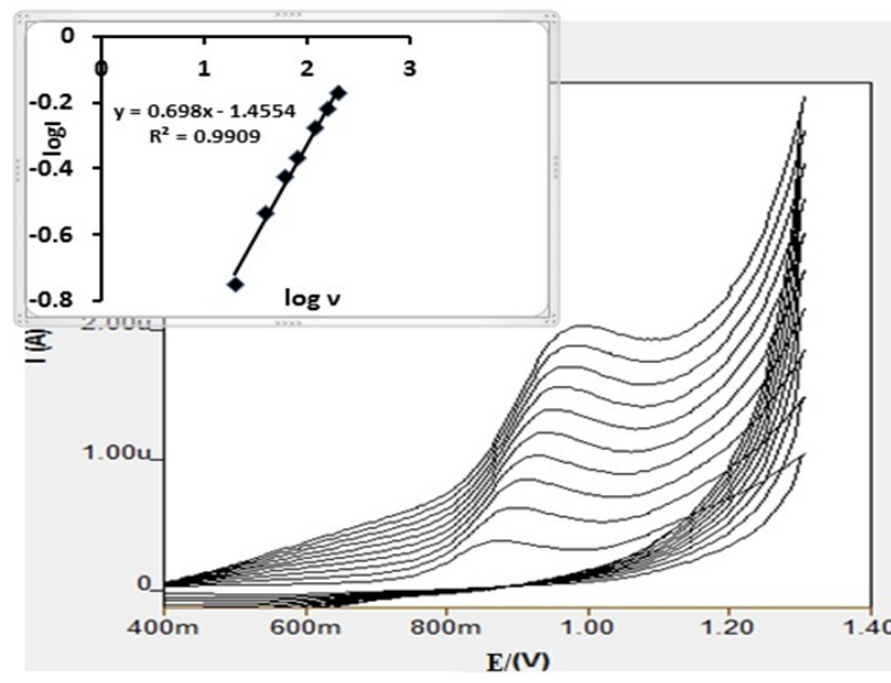

Fig. 8. The plot of logarithm of peak current vs. the logarithm of the scan rate of BRX at FCPEs

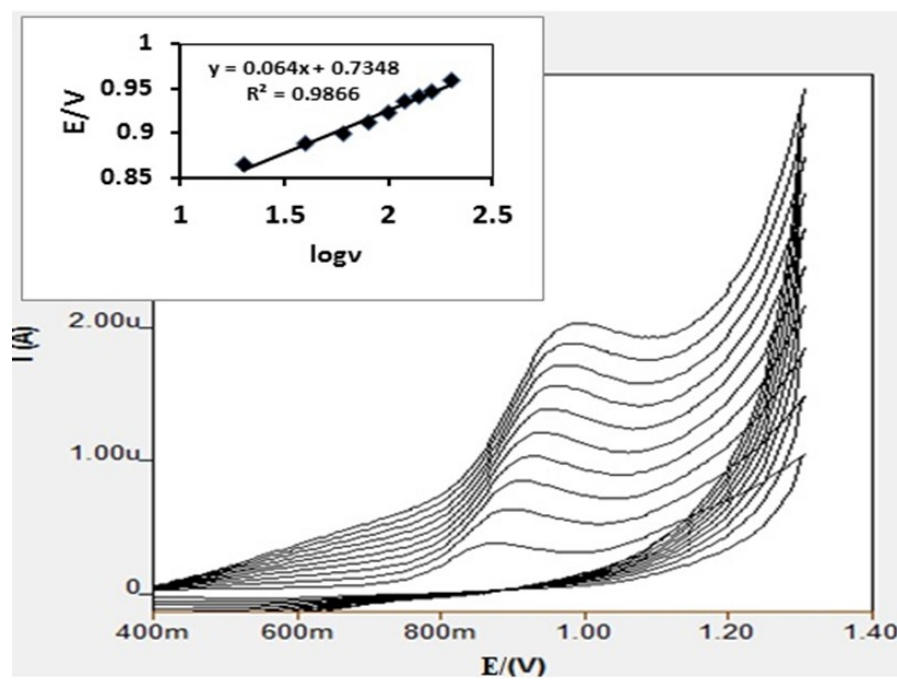

Fig. 9. Dependence of peak potential on the logarithm of the scan rate of BRX at FCPEs.

$$
\log \operatorname{Ip}(\mu \mathrm{A})=0.698 \log v\left(\mathrm{Vs}^{-1}\right)+1.455 \mathrm{r}^{2}=0.990
$$

The value (0.698) in between $0.5-1.0$ of the slope is observed, suggesting a mixed diffusion-adsorption controlled occurring at FCPEs [15].

In case of irreversible electrode process, the peak potential (Ep) and scan rate (v) are defined by the following Laviron equation.[16]

$$
\mathrm{Ep}=\mathrm{E}^{\mathrm{o}}+2.303 \mathrm{RT} / \alpha \mathrm{nF}\left[\log \mathrm{RTK}^{\mathrm{o}} / \alpha \mathrm{nF}+\log v\right]
$$

where $\alpha$ is the electron transfer coefficient, $\mathrm{n}$ is the number of electrons, $\mathrm{T}$ is the temperature $(298 \mathrm{~K}), \mathrm{R}$ is the gas constant $(8.314 \mathrm{~J} \mathrm{~K}$ $\left.\mathrm{mol}^{-1}\right)$ and $\mathrm{F}$ the Faraday constant $\left(96485 \mathrm{C} \mathrm{mol}^{-1}\right)$, respectively. Thus we can calculate $\alpha$ from the slope of the relation between Ep versus $\log v$. In this case, the slope value is 0.064 ; $\alpha$ n value was calculated to be 0.906 . Generally, $\alpha$ (electron transfer coefficient) was assumed to be

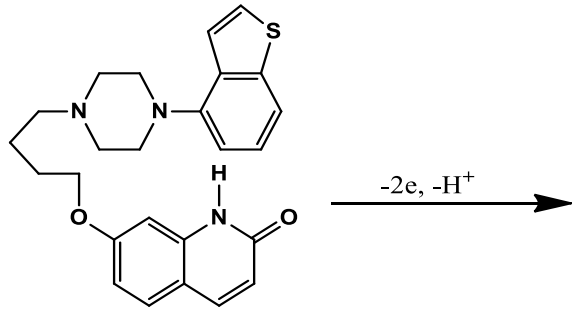

Brexpiprazole

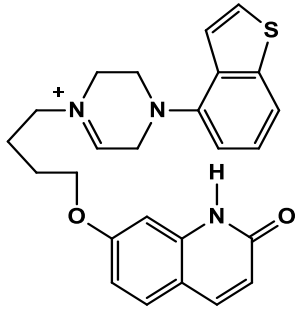

Oxidation product
Fig. 10. Proposed oxidation mechanism of BRX at FCPEs.

0.5 . Thus, the value of electrons number $n=1.81(\approx 2)$ was obtained confirming the proposed electro-oxidation mechanisms of BRX as shown in (Fig. 9). Same parameter ( $\alpha$ n) was calculated from Eq.(4) in which the difference between peak potential and half-peak potential is expressed [17] for cyclic voltammograms and it was calculated to be 48 $\mathrm{mV}$.

$/ \mathrm{E}_{\mathrm{p}}-\mathrm{E}_{\mathrm{p}, \mathrm{h}} /=\frac{(1.857 R T)}{\beta n F}$ and at $25^{\circ} \mathrm{C} / \mathrm{E}_{\mathrm{p}}-\mathrm{E}_{\mathrm{p}, \mathrm{h}} /=\frac{(47.7)}{\beta n}$

In this equation, $E_{\mathrm{p}, \mathrm{h}}$ is half peak potential in $\mathrm{mV}$ and other abbreviations have the same meaning as in Eq.(3). an value was calculated to be 0.993 . Thus, the value of electrons number $n=1.98(\approx 2)$ When these results and the limiting values for the charge transfer coefficient (between 0 and 1.0) [17-19] were evaluated, the number of electrons in electrode process could be predicted as 2 .

\subsection{Proposed oxidation mechanism of $B R X$}

Depending on former results, two electrons and one proton participate in the electrode process of BRX at FCPEs (Fig. 10) which is compatible with previously results for oxidation of piperazine ring [20-22].

\subsection{Method Validation}

The analytical method was validated according to the international conference on Harmonization (ICH) [23].

\subsection{Linearity and range}

Linearity relationship was verified over the concentration ranges indicated in Table 1 for both AS-DPV and AS-SWV techniques as shown in (Figs. 11 and 12). Statistical analysis of the data gave high values of square correlation coefficient $\left(\mathrm{R}^{2}\right)$ and small values of standard deviation (SD) and relative standard deviation (RSD) which figures out the low scattering of the points around the calibration graph and proved linearity of the method over the specified concentration range $[24,25]$ (Table 1).

\subsection{Limit of detection (LOD) and limit of quantita- tion (LOQ)}

LOD and LOQ were calculated according to the following equations as specified by ICH guidelines.

$$
\begin{aligned}
& \mathrm{LOD}=3.3 \sigma / \mathrm{S} \\
& \mathrm{LOQ}=10 \sigma / \mathrm{S}
\end{aligned}
$$

Where $\sigma$ is the standard deviation of $y$-intercepts of regression lines and $\mathrm{S}$ is the slope of the calibration curve. The results are summarized in Table 1, indicated that the proposed methods is more sensitive than other reported methods to detect the lowest amount of BRX concentration.

\subsection{Accuracy}

The accuracy of the proposed voltammetric methods for the determination of BRX was studied. The results obtained were summarized in Tables (1) which confirmed that the proposed methods are accurate, as 


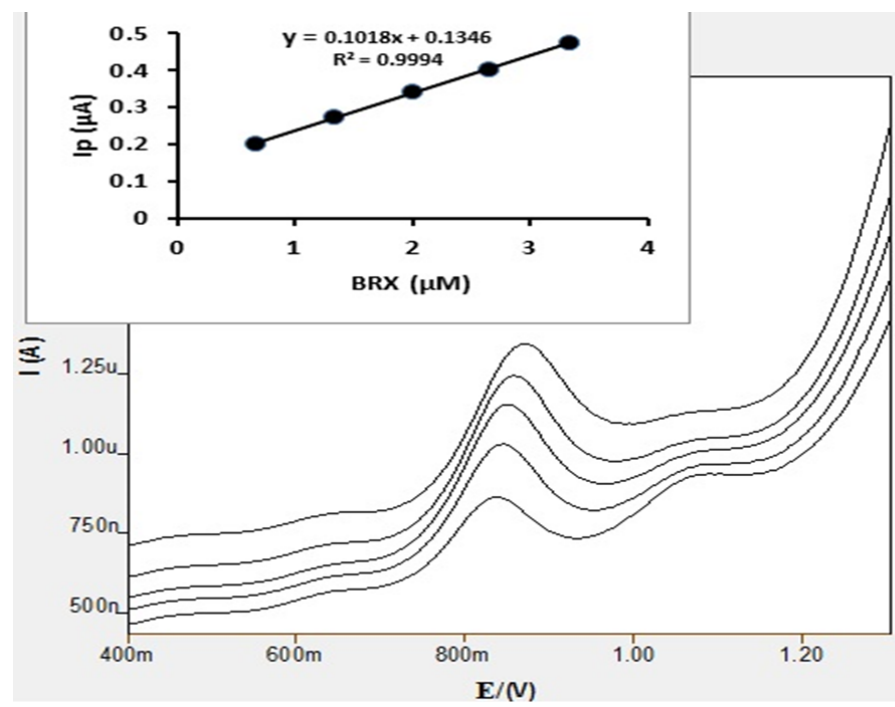

Fig. 11. Differential pulse anodic strippig voltammograms of solutions with different BRX concentrations in BR buffer of $\mathrm{pH} 4.0$, preconcentration time and preconcentration potentials are $50 \mathrm{~s}$ and $-0.5 \mathrm{~V}$, respectively.

indicated by the percentage recovery values. Accuracy Table 2 which indicates no matrix interference.

\subsection{Precision}

The intra- and inter-day precision was calculated by assaying freshly prepared solutions of analyte in triplicate on the same day (the repeatability) and on three different days (intermediate precision), respectively using the proposed voltammetric methods. The repeatability (intra-day) and intermediate precision (inter-day) of the results obtained by the proposed AS-DP and AS-SWV procedures were examined and the results indicated high precision of the proposed procedure and proved to be suitable for quality control of BRX (Table 1).

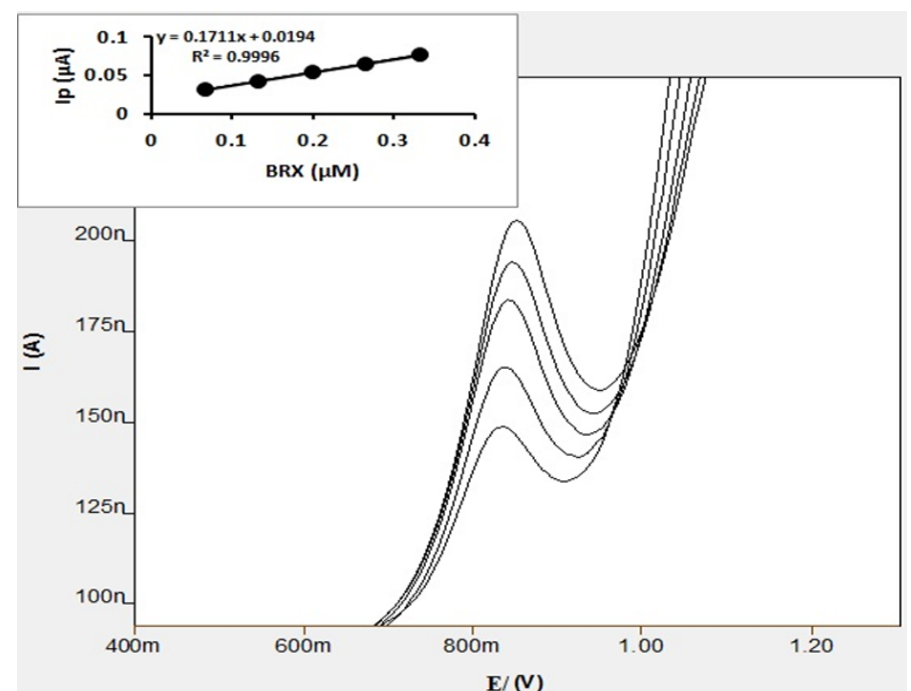

Fig. 12. Square-wave anodic strippig voltammograms of solutions with different BRX concentrations in BR buffer of $\mathrm{pH} 4.0$, preconcentration time and preconcentration potentials are $50 \mathrm{~s}$ and $-0.5 \mathrm{~V}$, respectively.

\subsection{Robustness}

The robustness of the proposed voltammetric method can be determined by studying an ability of the method to kept unaffected by even a small deliberate variation in method parameters conditions such as $\mathrm{pH}( \pm 0.1)$ and the resting time before each measurement $(5 \mathrm{~s} \pm 1 \mathrm{~s})$. It is applied by changing only parameter while the other conditions remain constant; no observable changes were noted in the results, confirming robustness of the procedure [26, 27]. These minor changes that may take place during the experimental operation did not affect the peak current intensity of the studied drug, indicating the reliability of the proposed method during normal usage (Table 1).

Table 1. Regression and validation data for the determination of BRX by the proposed voltammetric procedures at FCPEs.

\begin{tabular}{|c|c|c|c|}
\hline parameter & & AS-DP & AS-SW \\
\hline Working electrode potential (mV) & & 0.846 & 0.84 \\
\hline Range $\left(\mathrm{mol} \mathrm{L}^{-1}\right)$ & & $6.64 \times 10^{-7}-3.2 \times 10^{-6}$ & $6.64 \times 10^{-8}-3.2 \times 10^{-7}$ \\
\hline Slope $(\mu \mathrm{A})$ & & 0.1018 & 0.1711 \\
\hline Intercept $(\mu \mathrm{A})$ & & 0.1346 & 0.0194 \\
\hline Square Correlation coefficient $\left(\mathrm{R}^{2}\right)$ & & 0.9994 & 0.9996 \\
\hline $\operatorname{LOD}\left(\mathrm{mol} \mathrm{L}^{-1}\right)$ & & $1.74 \times 10^{-7}$ & $1.31 \times 10^{-8}$ \\
\hline LOQ $\left(\mathrm{mol} \mathrm{L}^{-1}\right)$ & & $5.3 \times 10^{-7}$ & $3.99 \times 10^{-8}$ \\
\hline Accuracy $(\% \mathrm{R})$ & & 98.77 & 100.98 \\
\hline & Repeatability $^{\mathrm{a}}$ & 1.213 & 0.879 \\
\hline Precision(\%KSD) & Intermediate precision $^{\mathrm{b}}$ & 0.987 & 0.642 \\
\hline Robustness $^{\mathrm{c}}$ ( Mean $\pm \%$ RSD) & & $98.45 \pm 1.05$ & $101.45 \pm 1.45$ \\
\hline
\end{tabular}

${ }^{a}$ Average of three different concentrations for brexpiprazole repeated three times within the day. ${ }^{b}$ Average of three different concentrations for brexpiprazole repeated three times in three days. ${ }^{c}$ Variation in method parameters such as $\mathrm{pH}$ of the sample .

Table 2. Recovery study of BRX by standard addition technique using the proposed voltammetric procedures at FCPEs.

\begin{tabular}{|c|c|c|c|c|c|c|c|}
\hline Standard added $\times 10^{-6}$ & Tablet taken $\times 10^{-6}$ & Found $\times 10^{-6}$ & Recovery \% & Standard added $\times 10^{-7}$ & Tablet taken $\times 10^{-7}$ & Found $\times 10^{-7}$ & Recovery \% \\
\hline & AS-DP & & & \multicolumn{4}{|c|}{ AS-SWV } \\
\hline 0.99 & \multirow{7}{*}{0.5} & 0.98 & 98.99 & 0.99 & \multirow{5}{*}{0.5} & 0.97 & 97.97 \\
\hline 1.33 & & 1.34 & 100.75 & 1.33 & & 1.32 & 99.25 \\
\hline 1.65 & & 1.66 & 100.60 & 1.65 & & 1.64 & 99.39 \\
\hline 1.99 & & 1.98 & 99.49 & 1.99 & & 2.01 & 101.00 \\
\hline 2.37 & & 2.35 & 99.15 & 2.37 & & 2.38 & 100.42 \\
\hline mean & & 99.80 & & & 99.60 & & \\
\hline$\%$ RSD & & 0.826 & & & 1.172 & & \\
\hline
\end{tabular}




\subsection{Application}

The proposed method was applied to the quantitative analysis of BRX in pharmaceuticals preparations. There are no any oxidative compounds or extra noises peaks found in different matrices are seen in the potential range of an interested the analytical peak. The results obtained assure the validity of the proposed voltammetric methods for the determination of BRX in tablets. These results reveal that both AS-DP and AS-SWV methods had adequate precision and accuracy and consequently can be applied to the determination of BRX in pure and pharmaceutical preparations without any interference. The results obtained by the proposed voltammetric and the reported methods [4] were statistically compared, confirming that a good accuracy and precision of the proposed method for the analysis of the BRX in its pharmaceutical dosage form, as shown in Table 3. By applying of t-test and F-test at 95 $\%$ confidence level, there are no significant differences [28].

\section{CONCLUSION}

In the present work, novel sensor based on modification of CPEs with functionalized carbon nanotubes was used for electrochemical determination of BRX. The advantage of the functionalization of carbon nanotubes was enhancing the sensitivity of the CPEs towards BRX. The results showed that the method is a simple, sensitive, easyto-handle, and rapid for the determination of BRX in pure and pharmaceutical preparations with good precision, accuracy, selectivity and very low detection limit. A high percentage of recovery and low $\%$ RSD values of proposed anodic stripping methods indicate that these methods are suitable for the routine determination of the drug in quality control laboratories without interference from other ingredients.

\section{ACKNOWLEDGMENT}

The authors thank Department of Pharmaceutical Analytical Chemistry, Faculty of Pharmacy, Al-Azhar University for supporting this work.

\section{REFERENCES}

[1] L. Citrome, Int J Clin Pract., 69, 978 (2015).

[2] S. Das, P. Barnwal, W.A. Blessed, S Mondal, I. Saha,Ther. Adv. Psychopharmacol., 6, 39 (2016).

[3] Wikipedia [internet], [reviewed 2017 Sep 2; cited 2017 Sep 27]. Available from:https://en.wikipedia.org/wiki/ Brexpiprazole, oct. 4th, 2017.

[4] A. Sravani , C.H.N. Durga, U. Divya, C.H. Suneetha, P. Suresh, B. T. Rao, C. Sudheer,. Indo. Am. J. Pharm. Res., 7, 8560 (2017).

[5] J. R. Enders, S.G. Reddy, E. C. Strickland, G. L. McIntire, Clin. Mass. Spectrom., 6, 21 (2017).

[6] F. Sayin, S. Kir, J. Pharm. Biomed. Anal., 25, 153 (2001).

[7] S.A. Ozkan, B. Uslu, P. Zuman, Anal. Chim. Acta., 457, 265

Table 3. Statistical comparison of the results obtained by the proposed voltammetric and the reported methods.

\begin{tabular}{lccc}
\multicolumn{1}{r}{ parameter } & AS-DP & AS-SWV & Reported method \\
\hline $\mathrm{N}^{*}$ & 5 & 5 & 5 \\
$\mathrm{X}^{-* *}$ & 99.61 & 99.56 & 99.26 \\
$\mathrm{SD}$ & 0.806 & 0.873 & 1.031 \\
Variance & 0.649 & 0.609 & 1.039 \\
Student's t-test & 0.574 & 0.478 & \\
& $(2.306)^{* * *}$ & $(2.306)^{* * * *}$ & \\
F-value & 1.600 & 1.706 & \\
& $(6.338)^{* * *}$ & $(6.338)^{* * *}$ & \\
\hline
\end{tabular}

* Number of experiments; $* *$ the mean of percent recovery of brexpiprazole. $* * *$ The values in parenthesis are tabulated values of " $t$ "and "F" at $(\mathrm{P}=0.05)$. (4) HPLC method using a mobile phase consists of $0.1 \% \mathrm{v} / \mathrm{v}$ Formic acid in water: Methanol (35:65).
(2002).

[8] J. Heyrovsky, P. Zuman, in: Practical Polarography, Academic Press, New York, 163, 1968.

[9] P. M. Kadam, N. L.Tarwal, S. S. Mali, H. P. Deshmukh and P. S. Patil, Electrochimica Acta, 58, 556 (2011).

[10]S. H. Pisal, N. S. Harale, T. S. Bhat, H. P. Deshmukh,and P. S. Patil, (IOSR-JAC), 7, 49 (2014).

[11]Attia A.K, Badawy A.M., Abd-Elhamid S.G., RSC Adv., 6, 39605 (2016).

[12]B. Rezaei, S. Damiri, Sens. Actuators. B -Chem., 13, 324 (2008).

[13]B. Rezaei, Z.M. Zare, Anal. Lett., 41, 2267 (2008).

[14]K.M. Naik, S.T. Nandibewoor, Sens. Actuators. A- Phys., 212, 127 (2014).

[15]B. Dogan-Topal, B. Bozal-Palabıy1k, B. Uslu, S.A. Ozkan, Sens. Actuators. B- Chem., 177, 841 (2013).

[16]E. Laviron, J. Electroanal. Chem. Interfacial Electrochem., 101, 19 (1979).

[17]C.M.A. Brett, A.M.O. Brett, Electrochemistry, Principles, Methods and Applications, 1st ed., Oxford University Press, New York, 1993.

[18]J. Wang, Analytical Electrochemistry, 2nd ed., A John Wiley \& Sons, Inc. Publication, New York, 2000.

[19]H. Lund, O. Hammerich (Eds.), Organic Electrochemistry, 4th ed., Marcel Dekker Inc., New York, 2001.

[20]A. Shalaby,W. S. Hassan, H.A.M. Hendawy, A.M. Ibrahim. J. Electroanal. Chem., 763, 51 (2016).

[21]J.M. Kauffmann, J.C. Vire, G.J. Patriarche, L.J. Nunez-Vergara, J.A. Squella, Electrochim. Acta, 32, 1159 (1987).

[22]R.N. Hegde, N.P. Shetti, S.T. Nandibewoor, Talanta, 79, 361 (2009).

[23]International Conference on Harmonization, ICH Harmonised Tripartite Guideline. Validation of analytical procedure: text and methodology, Q2 (R1). International Conference on Harmonization, Geneva, 2005.

[24]M. Rizk, E. A. Taha, S. Mowaka, Y. M. Abdallah, J. Chromatogra. Sci., 53, 742 (2015).

[25]M.F. Ayad, N. Magdy, Chemical and Pharmaceutical Bulletin., 63, 443 (2015)

[26]The united States Pharmacopoeia, National Formulary, "25th ed. United States Pharmacopoeia Convention: Rockville, MD” [USA] (2007).

[27]M. El-Tohamy, S. Razeq, M. El-Maamly, A. Shalaby, Cen. Eur. J. Chem., 8, 937 (2010).

[28]Armitage P, Berry G. Statistical methods in medical research. 3rd ed. Oxford (UK): Blackwell; 1994. 